\title{
Monosynaptic and Polysynaptic Feed-Forward Inputs to Mitral Cells from Olfactory Sensory Neurons
}

\author{
Marion Najac, ${ }^{1,2,3 *}$ Didier De Saint Jan, ${ }^{1,2,3 *}$ Leire Reguero, ${ }^{4}$ Pedro Grandes, ${ }^{4}$ and Serge Charpak ${ }^{1,2,3}$ \\ ${ }^{1}$ Institut National de la Santé et de la Recherche Médicale Unité 603, Paris, France, ${ }^{2}$ Centre National de la Recherche Scientifique Unité Mixte de Recherche \\ 8154, Paris, France, ${ }^{3}$ Universite Paris Descartes, Paris, France, and ${ }^{4}$ Department of Neurosciences, Faculty of Medicine and Dentistry, Basque Country \\ University, Bilbao, Spain
}

Olfactory sensory neurons (OSNs) expressing the same odorant receptor converge in specific glomeruli where they transmit olfactory information to mitral cells. Surprisingly, synaptic mechanisms underlying mitral cell activation are still controversial. Using patch-clamp recordings in mouse olfactory bulb slices, we demonstrate that stimulation of OSNs produces a biphasic postsynaptic excitatory response in mitral cells. The response was initiated by a fast and graded monosynaptic input from 0SNs and followed by a slower component of feedforward excitation, involving dendro-dendritic interactions between external tufted, tufted and other mitral cells. The mitral cell response occasionally lacked the fast OSN input when few afferent fibers were stimulated. We also show that OSN stimulation triggers a strong and slow feedforward inhibition that shapes the feedforward excitation but leaves unaffected the monosynaptic component. These results confirm the existence of direct OSN to mitral cells synapses but also emphasize the prominence of intraglomerular feedforward pathways in the mitral cell response.

\section{Introduction}

Olfactory sensory neurons (OSNs) converge in the olfactory bulb onto specific glomeruli where they transmit sensory information to mitral and tufted cells, the principal neurons of the bulb. OSNs express only one type of odorant receptor (OR), and each glomerulus is innervated by OSNs expressing the same OR (Ressler et al., 1994; Vassar et al., 1994; Malnic et al., 1999). Mitral and tufted cells send their apical dendrite in a single glomerulus and thus integrate sensory inputs from a specific set of OSNs (Wachowiak and Shipley, 2006; Wilson and Mainen, 2006). However, it remains debated how OSNs activate mitral and tufted cells.

In olfactory bulb slices, a single electrical stimulation of OSNs evokes a complex long-lasting depolarization called LLD in mitral cells (Chen and Shepherd, 1997; Carlson et al., 2000; Schoppa and Westbrook, 2001; De Saint Jan and Westbrook, 2007). This response potentially provides a critical amplification step of the incoming sensory information. Multiple evidence indicates that the slow component of the LLD is a feedforward excitation mediated by intraglomerular dendro-dendritic interactions (Carl-

\footnotetext{
Received Jan. 31, 2011; revised March 24, 2011; accepted April 22, 2011

Author contributions: D.D.S.J. and S.C. designed research; M.N., D.D.S.J., L.R., and P.G. performed research; M.N., D.D.S.J., L.R., and P.G. analyzed data; D.D.S.J. and S.C. wrote the paper.

This work was supported by the Fondation pour la Recherche Médicale, the Fondation Bettancourt Schueller, the Human Frontier Science Program Organisation, and the Leducq Foundation. M.N. was supported by a fellowship from the Ministère de l'Enseignement Supérieur et de la Recherche and Leire Reguero by a Predoctoral Fellowship from The Basque Country Government (BF107.286). We thank Jonathan Bradley, Philippe Ascher, Etienne Audinat, and Brandon Stell for their critical comments, and Gwénaëlle Bouchery for technical assistance.

${ }^{*} M$.N. and D.D.S.J. contributed equally to this work.

Correspondence should be addressed to either Didier De Saint Jan or Serge Charpak, Université Paris Descartes, 45, rue des Saints-Pères 75006 Paris, France, E-mail: didier.desaintjan@parisdescartes.fr or serge.charpak@ parisdescartes.fr.

DOI:10.1523/JNEUROSCI.0527-11.2011

Copyright $\odot 2011$ the authors $\quad 0270-6474 / 11 / 318722-08 \$ 15.00 / 0$
}

son et al., 2000; Schoppa and Westbrook, 2001; De Saint Jan and Westbrook, 2007; De Saint Jan et al., 2009). However, the nature of these dendro-dendritic interactions is still incompletely understood. The indirect activation pathway may be driven by external tufted (ET) cells, a class of hyperexcitable juxtaglomerular neurons (Hayar et al., 2004a,b; Liu and Shipley, 2008a) that fire before mitral cells in response to an OSN input (De Saint Jan et al., 2009). Indeed, firing of a single ET cell can drive LLDs in mitral cells (De Saint Jan et al., 2009). What initiates the LLD in response to OSN stimulation is a matter of debate. Some groups found that mitral cells respond to a stimulation of OSNs with an all-or-none LLD lacking the initial OSN input (Carlson et al., 2000; Gire and Schoppa, 2009). Gire and Schoppa (2009) thus proposed that the mitral cell response is entirely mediated by an ET cell-driven feedforward pathway. However, these results challenge the classical view that OSN axons make synapses onto mitral cells (Pinching and Powell, 1971; Kosaka et al., 2001; Shepherd, 2004). In contrast, we found that the mitral cell response is initiated by a fast monosynaptic input and increases in amplitude and duration with the stimulus strength (De Saint Jan and Westbrook, 2007; De Saint Jan et al., 2009). Thus, we proposed that the mitral cell LLD is initiated by a monosynaptic OSN input and followed by an ET cell-driven feedforward excitation (De Saint Jan et al., 2009).

Here, we used whole-cell and cell-attached recording in mouse olfactory bulb slices to analyze the synaptic mechanism leading to mitral cell activation. Focusing on the AMPA receptor (AMPAR)-mediated component of the mitral cell EPSC, we first closely examined the events that initiate the OSNevoked response. In a second part of this study, we analyzed the nature of the dendro-dendritic excitatory and inhibitory interactions that shape the slow component of the mitral cell response. 


\section{Materials and Methods}

Slice preparation. Experimental protocols were approved by INSERM Health guidelines. Horizontal olfactory bulb slices were prepared from 14 to $30 \mathrm{~d}$ old transgenic mice of either sex expressing the enhanced yellow fluorescent protein (EYFP) under the control of the $\mathrm{Kv} 3.1 \mathrm{~K}^{+}$ channel promoter (Metzger et al., 2002). Mice were killed by decapitation and the bulbs rapidly dissected in ice-cold oxygenated $\left(95 \% \mathrm{O}_{2}-5 \%\right.$ $\mathrm{CO}_{2}$ ) solution containing the following (in $\mathrm{mm}$ ): $83 \mathrm{NaCl}, 26.2 \mathrm{NaHCO} 3$, $1 \mathrm{NaH}_{2} \mathrm{PO}_{4}, 2.5 \mathrm{KCl}, 3.3 \mathrm{MgSO}_{4}, 0.5 \mathrm{CaCl}_{2}, 70$ sucrose, and $22 \mathrm{D}$-glucose, $\mathrm{pH} 7.3$ (osmolarity $300 \mathrm{mOsm} / \mathrm{L}$ ). Slices $(300 \mu \mathrm{m}$ ) were cut using a Leica VT1000S vibratome in the same solution, incubated for 30-40 min at $34^{\circ} \mathrm{C}$, and stored at room temperature in a regular artificial CSF (ACSF) until use. ACSF contained the following (in $\mathrm{mm}$ ): $125 \mathrm{NaCl}, 25 \mathrm{NaHCO}_{3}$, $2.5 \mathrm{KCl}, 1.25 \mathrm{NaH}_{2} \mathrm{PO}_{4}, 1 \mathrm{MgCl}_{2}, 2 \mathrm{CaCl}_{2}$, and $25 \mathrm{D}$-glucose, continuously bubbled with $95 \% \mathrm{O}_{2}-5 \% \mathrm{CO}_{2}$.

Cell identification. EYFP fluorescence was used to identify mitral and tufted cells with an intact primary dendrite and the glomerulus into which they projected. Tufted cells had a soma found dispersed throughout the external plexiform layer, a mitral-like morphology, a thick apical dendrite projecting into a single glomerulus, and lateral dendrites running through the external plexiform layer (Christie et al., 2001; Kiyokage et al., 2010). Unlike mitral and tufted cells, external tufted cells do not express EYFP in our transgenic line, are located in the glomerular layer, and do not have lateral dendrites. They were identified with additional functional criteria as previously described (Hayar et al., 2004b; De Saint Jan et al., 2009).

Electrophysiological recordings. Experiments were conducted at 32$34^{\circ} \mathrm{C}$ on an upright microscope (Olympus BX51WI) with differential interference contrast (DIC) optics. In most of the recordings, OSNevoked AMPAR-mediated mitral cell responses were isolated in the presence of D-2-amino-5-phosphonopentanoic acid (D-AP5) $(50 \mu \mathrm{M})$ and 7-(hydroxyimino)cyclopropa[b]chromen-1a-carboxylate ethyl ester (CPCCOEt) $(100 \mu \mathrm{M})$ diluted in ACSF to block NMDA and mGlu1 receptors, respectively. Gabazine $(2-4 \mu \mathrm{M})$ was included when indicated to inhibit $\mathrm{GABA}_{\mathrm{A}}$ receptors. Voltage-clamp recordings were made with patch pipettes $(\sim 2-4 \mathrm{M} \Omega$ ) containing the following (in mM): $120 \mathrm{Cs}-$ $\mathrm{MeSO}_{3}, 20$ tetraethylammonium-Cl, 5 4-aminopyridine, $2 \mathrm{MgCl}_{2}, 0.025$ $\mathrm{CaCl}_{2}$, 1 EGTA, 4 Na-ATP, $0.5 \mathrm{Na}$-GTP, and 10 HEPES, pH 7.3 (Osm/L $\sim 280$ ). Cell-attached recordings were made with pipettes filled either with intracellular solution or with ACSF. For ET cell recording and studies of synaptic transmission in paired recordings, we used an internal solution containing (in mM) $135 \mathrm{~K}$-gluconate, $2 \mathrm{MgCl}_{2}, 0.025 \mathrm{CaCl}_{2}, 1$ EGTA, 4 Na-ATP, 0.5 Na-GTP, 10 HEPES, and 10 glutamate, pH 7.3) (Osm/L $\sim 280)$. Glutamate was necessary to avoid transmitter depletion and the resulting run-down of the postsynaptic cell response (Ma and Lowe, 2007; De Saint Jan et al., 2009). Alexa-Fluor 594 (4 $\mu \mathrm{M}$ ) (Invitrogen) was also added to the internal solution to confirm the glomerular projection of the recorded cell. In some cases, biocytin (10 mM) was added to the intracellular solution for post hoc visualization. To visualize biocytin-filled cells, slices were fixed in $4 \%$ paraformaldehyde overnight, washed 3 times, and incubated in a permeabilizing solution containing Cy-5-conjugated streptavidin ( $1 \mu \mathrm{g} / \mathrm{ml}$; Jackson ImmunoResearch) for $1 \mathrm{~d}$. After 3 wash cycles with PBS, sections were mounted. Labeled cells were imaged with a confocal microscope (Zeiss LSM 510).

Recordings were made with a multiclamp 700A amplifier (Molecular Devices), filtered at $2-4 \mathrm{kHz}$, and digitized at $10 \mathrm{kHz}$ using Clampex 9 software (Molecular Devices). In current-clamp recordings, a constant hyperpolarizing current was injected to maintain the cell at a potential of $-60 /-70 \mathrm{mV}$. In voltage-clamp recordings, access resistance $\left(\mathrm{R}_{\mathrm{a}}\right)$ were usually $<10 \mathrm{M} \Omega$ for mitral cells and $<20 \mathrm{M} \Omega$ for tufted and ET cells and were not compensated. Cells with $\mathrm{R}_{\mathrm{a}}$ that changed $>30 \%$ during the recording were rejected from the analysis. Most of the recordings were made at a holding potential of $-70 \mathrm{mV}$, unless otherwise indicated. Voltages indicated in the paper were corrected for a junction potential of $10 \mathrm{mV}$ (for the Cs-based internal solution) estimated with the Clampex software.

Large bundles of OSN axons entering the glomerulus can be seen with DIC optics. They were stimulated using a theta pipette filled with ACSF and positioned precisely on a visible bundle as far as possible (50-100 $\mu \mathrm{m})$ from the glomerulus into which they projected. For distant stimulation, the theta pipette was positioned in the nerve layer at $\sim 3$ glomeruli away from the glomerulus into which the recorded cell projected its dendrites. The electrical stimulus (100-200 $\mu \mathrm{s})$ was delivered using an isolator-11 Stimulus Isolation Unit (Molecular Devices) or an ISO STIM O1D (NPI Electronics). In paired recordings, action potentials were elicited in the presynaptic cell by injecting a short $(2 \mathrm{~ms})$ depolarizing pulse $(0.5-2 \mathrm{nA})$ every $10 \mathrm{~s}$.

Analysis. Data were digitally filtered at $1-2 \mathrm{kHz}$ when necessary and analyzed using Axograph X (Axograph Scientific) and Igor Pro (WaveMetrics). The peak of the monosynaptic component being sometimes difficult to distinguish within the rising phase of the mitral cell response, we defined its onset as the intercept of a linear fit of the initial rising phase of the response and the baseline axis. For IPSCs, we measured their onset at $5 \%$ of the first outward peak following the stimulation. The latency of EPSC/IPSC was defined as the time interval between the beginning of the stimulation artifact and the onset of the EPSC/IPSC. The jitter of the response was defined as the SD of the latency. Action potentials were detected with NeuroMatic (http://www.neuromatic.thinkrandom. $\mathrm{com} /$ ). To characterize OSN-evoked firing, we measured the latency and jitter of the first spike and counted spikes across a $150 \mathrm{~ms}$ time window after the stimulus, i.e., the approximate duration of the AMPARmediated EPSC. Five cells recorded in regular ACSF were excluded from the analysis because of intense spontaneous firing or because gabazineinduced epileptic activity.

We used the Wilcoxon matched-paired test (two-tailed) to compare two sets of data acquired from the same population in different conditions and the unpaired $t$ test to compare two sets of data acquired from different populations. Results are expressed as mean \pm SD.

Immunocytochemistry for electron microscopy. Slices from olfactory bulb were extensively washed in $0.1 \mathrm{M}$ phosphate buffer (PB), pH 7.4, and incubated in $1 \%$ hydrogen peroxide in $0.1 \mathrm{M} \mathrm{PB}$ for $30 \mathrm{~min}$ at room temperature (RT) to block endogenous peroxidase activity. After several washes in $0.1 \mathrm{M} \mathrm{PB}$, sections were cryoprotected $(25 \%$ sucrose and $10 \%$ glycerol in $0.05 \mathrm{M} \mathrm{PB}$ ) for $1 \mathrm{~h}$ at RT, then freeze-thawed three times over liquid nitrogen and resliced at $50 \mu \mathrm{m}$ on a vibratome. Sections were washed with a solution containing $1 \%$ bovine serum albumin and $0.02 \%$ saponin prepared in Tris-HCl buffered saline, $\mathrm{pH}$ 7.4. Tissue was processed by a conventional avidin-biotin peroxidase complex method (Elite, Vector Laboratories). Sections were incubated subsequently with 0.05\% 3,3'-diaminobenzidine-tetrahydrochloride and $0.01 \%$ hydrogen peroxide in $0.1 \mathrm{M} P B$ for $5 \mathrm{~min}$ and washed in $0.1 \mathrm{M} \mathrm{PB}$. Stained sections were osmicated ( $1 \% \mathrm{OsO}_{4}$ in $\left.0.1 \mathrm{M} \mathrm{PB}, \mathrm{pH} 7.4,20 \mathrm{~min}\right)$, dehydrated in graded alcohols to propylene oxide, and plastic embedded flat in Epon 812. Ultrathin sections $(80 \mathrm{~nm})$ were collected on mesh nickel grids, stained with lead citrate, and examined in a PHILIPS EM208S electron microscopy. Tissue preparations were photographed by using a digital camera coupled to the electron microscope. Figure compositions, labeling, and minor adjustments in contrast and brightness were made using Adobe Photoshop (CS, Adobe Systems).

Drugs. 6-Nitro-7-sulfamoylbenzo[f] quinoxaline-2,3-dione (NBQX), DAP5, 2-(3-carboxypropyl)-3-amino-6-(4 methoxyphenyl)pyridazinium bromide (gabazine), 5-(aminomethyl)isoxazol-3-ol (muscimol), and CPCCOEt were purchased from Tocris Bioscience or Ascent Scientific.

\section{Results}

Stimulation of OSNs evokes a biphasic mitral cell response

OSNs were electrically stimulated with a theta pipette precisely positioned on a visible bundle of OSN axons converging into the glomerulus in which the recorded mitral cell projected its primary dendrite. AMPAR-mediated EPSCs were isolated in the presence of D-AP5, CPCCOEt, and gabazine which blocked NMDA, mGlu1, and $\mathrm{GABA}_{\mathrm{A}}$ receptors, respectively (Fig. $1 \mathrm{~A}$ ). Under these conditions the AMPAR-mediated response was biphasic with a fast-rising EPSC (10-90\% rise-time, $1.3 \pm 0.4 \mathrm{~ms}$ ) that peaked $4.4 \pm 0.8 \mathrm{~ms}$ after the stimulus followed by a slower EPSC (half-width, $52.9 \pm 29.6 \mathrm{~ms} ; n=8$ ) (Fig. $1 B$ ). The ampli- 
tude of the two components increased in a graded manner with the stimulus strength, and both were always present at all stimulation intensities above threshold (Fig. $1 B, C$ ). Mitral cells are electrically coupled to other mitral cells (Schoppa and Westbrook, 2002; Christie et al., 2005; Pimentel and Margrie, 2008) and to ET cells (De Saint Jan et al., 2009), suggesting that gap-junction-mediated inward currents from other neurons may contribute to the evoked response. However, an outward response with a similar biphasic time course was seen in mitral cells held at a positive holding potential $(n=7)$ (Fig. $1 C)$ suggesting that both components reflect glutamatergic inputs onto the recorded mitral cell. Moreover, the fast and slow components of the EPSC were abolished by the AMPAR antagonist NBQX (10 $\mu \mathrm{M}, n=13$ ) (Fig. $1 C$ ) or when the stimulating pipette was moved a few tens of micrometers away from the bundle of OSNs $(n=4)$ (Fig. 1D). This indicates that the electrical shocks used in this study produced a local stimulation that did not evoke a direct electrical activation of the mitral cell primary dendrites. Biphasic responses with similar properties were observed in tufted cells located in the external plexiform layer $(n=10)$ (Fig. $1 E)$.

\section{OSNs make axo-dendritic synapses onto mitral cell dendrites}

The initial component of the biphasic AMPAR-mediated EPSCs had a short latency onset that occurred with little time variability consistent with a direct monosynaptic input. To further demonstrate the existence of OSN to mitral cells synapses we conducted two additional experiments. First, we did paired recording to compare the fast component of the mitral cell response with the simultaneously recorded monosynaptic OSN-mediated EPSC of an ET cell projecting into the same glomerulus (Hayar et al., 2004a). They occurred nearly simultaneously with similar onset latencies $(2.5 \pm 0.2 \mathrm{~ms}$ for the mitral, $2.2 \pm 0.4 \mathrm{~ms}$ for the ET cell; $p>0.1)$ and small jitters $(0.18 \pm 0.10 \mathrm{~ms}$ for the mitral cell, $0.08 \pm 0.07 \mathrm{~ms}$ for the ET cell, $n=7$ pairs; $p>0.08$ ) (Fig. $1 F$ ). We then searched for morphological correlates of the OSN to mitral cells connections. Classical electron microcopy studies have already shown OSN terminals forming asymmetric synapses onto presumed mitral/tufted cell dendrites (Pinching and Powell, 1971). However, mitral, tufted, and ET cell dendrites are indistinguishable at the electron microcopy level (Pinching and Powell, 1971; Wachowiak and Shipley, 2006), whereas functional studies suggest these cell types should not be considered as a homogenous population (Christie et al., 2001; Hayar et al., 2004a,b; Nagayama et al., 2004). Therefore, we filled mitral cells with biocytin and examined with electron microscopy if their labeled primary dendrites receive OSN synapses ( $n=4$ cells). The analysis revealed that labeled dendrites were
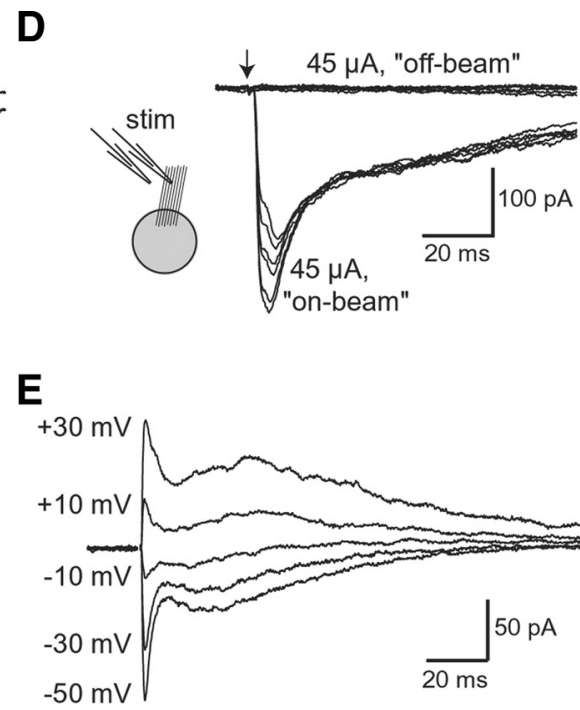

$\mathbf{F}$
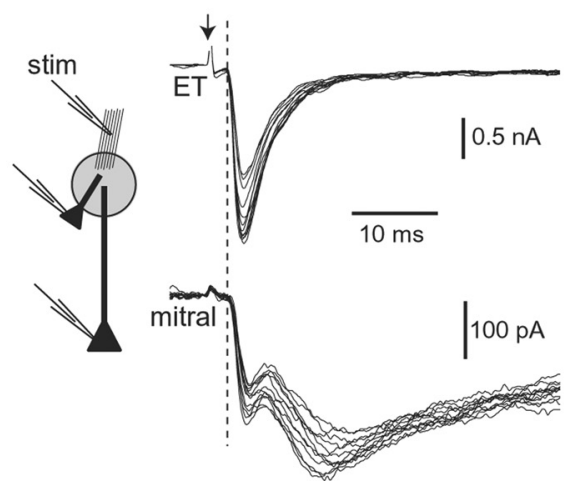

Figure 1. Stimulation of OSNs evokes a biphasic AMPAR-mediated response in mitral cells. $\boldsymbol{A}$, Left, OSNs were stimulated with a pipette (stim) precisely positioned on a visible bundle of OSNs converging in the same glomerulus than the recorded mitral cell. mediated EPSCs evoked by increasing stimulation intensities (35-100 $\mu \mathrm{A})$. Four raw traces are superimposed in each case $\boldsymbol{E}$ Biphasic AMPAR-mediated EPSCs evoked in a tufted cell recorded at different holding potentials. $\boldsymbol{F}$, OSN-evoked AMPAR EPSC recorded simultaneously in an ET cell (top traces) and a mitral cell (bottom) projecting into the same glomerulus. Twelve OSNevoked responses are superimposed. Dashed line indicates the onset of the ET cell EPSC.

often surrounded by groups of synaptic terminals packed with spherical vesicles (Fig. 2). This organization in tightly packed clusters is considered as a signature of OSN terminals making axo-dendritic synapses onto postsynaptic mitral or tufted cell dendrites (Pinching and Powell, 1971; Kasowski et al., 1999).

\section{The ET cell driven disynaptic pathway dominates when few} afferents are stimulated

Our data so far strongly support the classical view that OSN to mitral cell synapses exist. This direct pathway is activated when a visible bundle of OSNs containing a significant number of axons is stimulated (Fig. 1). However, in a recent report, Gire and Schoppa (2009) failed to evoke mitral cell responses with a fast OSN-mediated input. Instead, they observed, like Carlson and colleagues before them (Carlson et al., 2000), slow-rising all-ornone and long-lasting EPSCs that occurred with variable latencies and resembled ET cell-driven feedforward LLDs. We ob- 

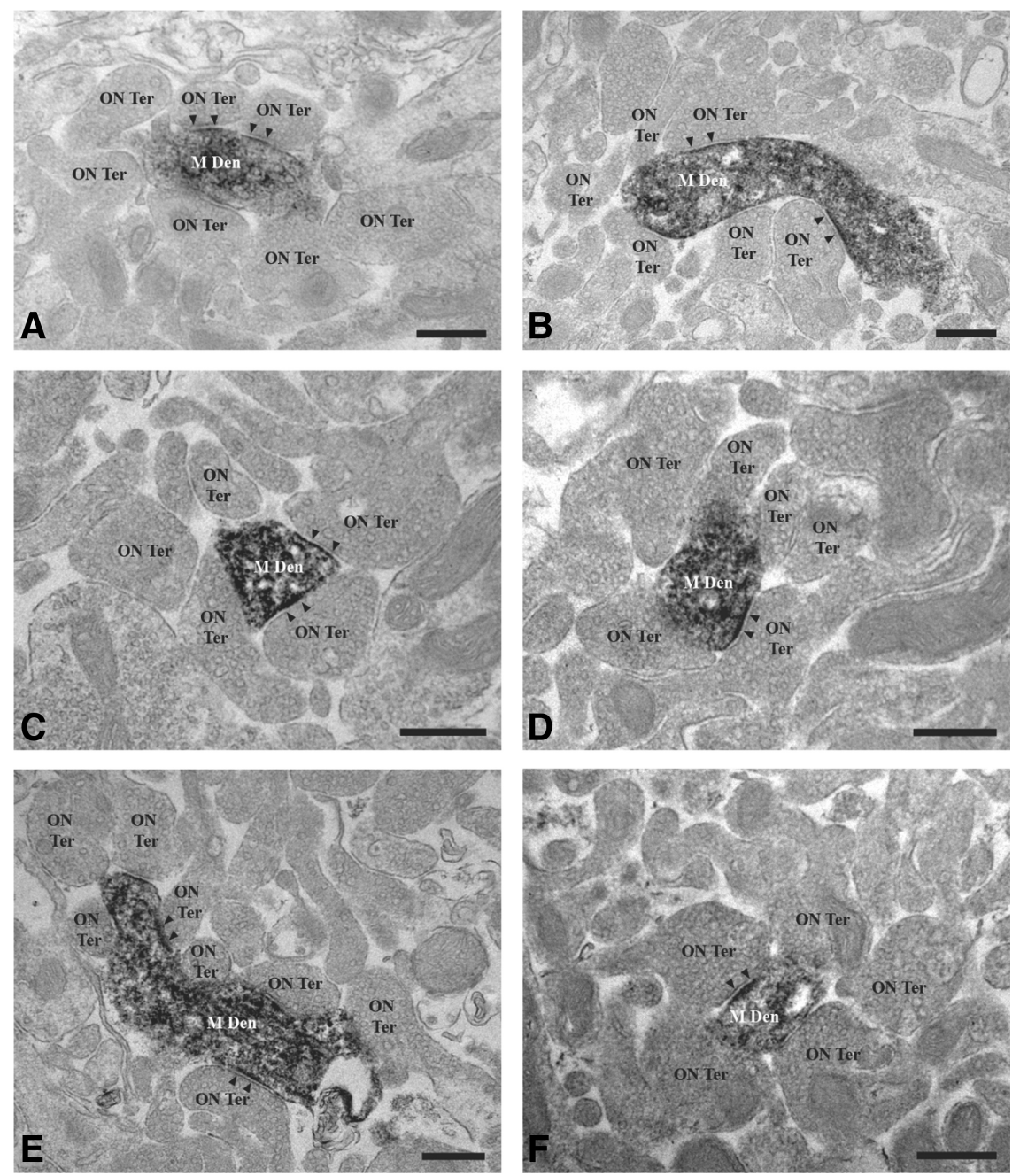

Figure 2. $\quad A-F$, Ultrastructural evidence for axo-dendritic synapses between OSNs and mitral cells. Electron photomicrographs of OSN terminals (ON Ter) identified as numerous synaptic boutons containing abundant spherical vesicles that make synapses of excitatory nature (arrowheads) on biocytin-filled mitral cell dendrites ( $M$ Den). Observe the typical cluster arrangement of OSN terminals surrounding mitral dendritic portions with immunodeposits. Scale bars: $0.4 \mu \mathrm{m}$.

served this kind of response under two particular conditions. First, when the visible bundle of OSNs was stimulated with minimal intensities that induced LLDs in $50-80 \%$ of the cases. Under these conditions, in 8 of 11 cells, LLDs occurred with variable latencies (Fig. 3A). Some of these LLDs lacked the monosynaptic input that was either absent or too small to be unambiguously detected. In 3 other cells, however, the LLD was always initiated by a fast component (data not shown). Some of these experiments of minimal stimulation were done in paired recording of ET and mitral cells as in the example shown in Figure $3 A(n=3$ pairs). Whereas the monosynaptic OSN input was small or absent in the mitral cell, a direct OSN input persisted in the ET cell with average amplitude of $217 \pm 70 \mathrm{pA}$. Another way to activate a smaller fascicle of OSNs is to stimulate the nerve layer far from the glomerulus of interest because OSN bundles tend to regroup when they approach their glomerulus (Potter et al., 2001). Accordingly, mitral cell responses lost their fast initial component when the stimulation pipette was moved away from the visible OSN fascicle at a more distant location in the nerve layer (Fig. $3 B)(n=10)$. When these experiments were done in paired recording mitral cell/ET cell, a monosynaptic OSN input persisted in the ET cell $(n=4$ pairs) with amplitudes $(200 \pm 160 \mathrm{pA})$ in the same range as those evoked by minimal stimulation of the visible OSN fascicle. In these four pairs, increasing the stimulation strength did not increase the ET cell response, confirming that the stimulation activated a small fascicle of OSNs. Together, these results suggest that the ET cell-driven feedforward pathway prevails when fewer afferent fibers are stimulated.

\section{Highly reliable dendro-dendritic connections promote the robust feedforward excitation of mitral cells}

A striking feature of the mitral cell response is the prominence of its slow component that was evoked by even the weakest stimulation. In some cells, this slow phase was clearly composed of asynchronous EPSCs (Fig. 1C). If it is mediated by disynaptic excitatory pathways, then reducing the network excitability should limit their contribution. Lowering the extracellular concentration of $\mathrm{Ca}^{2+}$ is a common approach to reduce the strength of disynaptic pathways. However, decreasing the $\mathrm{Ca}^{2+}$ concentration from $2-0.5 \mathrm{~mm}$ (together with an increase of $\left[\mathrm{Mg}^{2+}\right]$ to $2.5 \mathrm{~mm}$ ) increased the network excitability and the occurrence of spontaneous population bursts which made the results difficult to interpret (data not shown). We then tested the effect of a subsaturating concentration of NBQX (300-400 nM) that is expected to limit the strength of OSN inputs onto intermediary ET cells. This decreased the amplitude of the two components of the mitral cell response but did not isolate the fast component $(n=8$; data not shown). Finally, we applied a mixture of the $\mathrm{GABA}_{\mathrm{A}} \mathrm{R}$ agonist muscimol $(1-2 \mu \mathrm{M})$ and NBQX (200-300 nM). This decreased the amplitude of the mitral cell response (to $25 \pm 13 \%$ of control, $n=8$ ) and shortened its slow phase ( $1 / 4$ width $75.3 \pm 51.1 \mathrm{~ms}$ in control vs $22.5 \pm$ $9.85 \mathrm{~ms}$ in muscimol + NBQX, $n=8$ ) (Fig. 4). Yet, a slow component was still present in 4 of 8 cases and disappeared only at lower intensities of stimulation. Responses that lacked the slow component had a fast time course ( $1 / 4$ width, $12.1 \pm 4 \mathrm{~ms}$; decay, $8.7 \pm 2.2 \mathrm{~ms} ; n=7$ ) consistent with an isolated OSN-mediated monosynaptic EPSC.

The difficulty to isolate the OSN-mediated direct input indicates that glomerular feedforward excitatory circuits are extremely robust. Several mechanisms could underlie such robustness. Among these, ET cells have a low-firing threshold (De Saint Jan et al., 2009), membrane properties that promote hyperexcitability (Liu and Shipley, 2008a,b) and display large EPSPs upon minimal stimulation intensity (De Saint Jan et al., 2009). In addition, our paired recording experiments suggest that more OSNs may converge onto ET cells than onto mitral cells. The properties of the excitatory connections that mediate the slow component of the mitral cell response may also contribute to its robustness. In the glomerular network, excitatory connections (including chemical or mixed electro-chemical connec- 

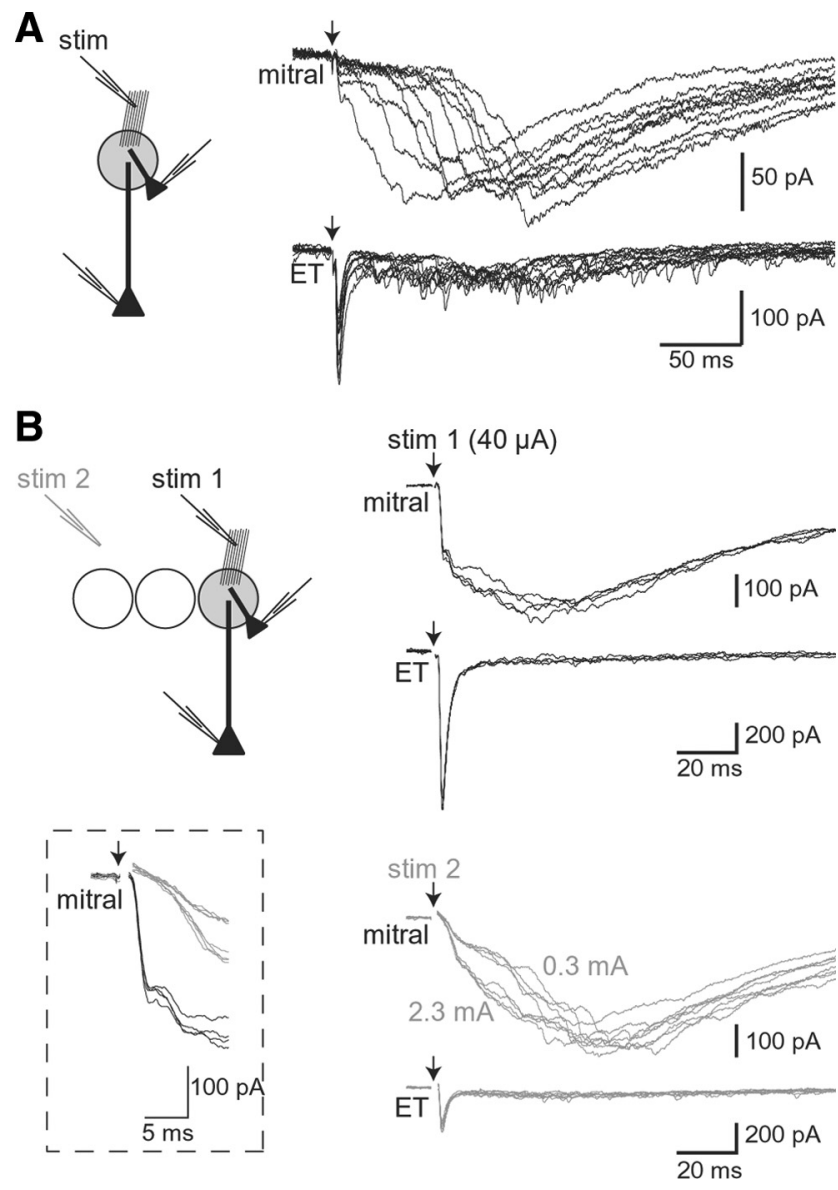

Figure 3. Mitral cell responses lacking the monosynaptic input are evoked only when few OSNs are stimulated. $A$, Paired recording of a mitral cell and an ET cell projecting into the same glomerulus. A large fascicle of OSNs was stimulated using an intensity $(35 \mu \mathrm{A})$ that evoked a response in $\sim 50 \%$ of the cases. Eleven successes are superimposed; failures are not shown for clarity. The monosynaptic input is lacking or difficult to detect in some of the mitral cell responses, whereas it is clearly visible in the ET cell. $\boldsymbol{B}$, Same recording configuration as in $\boldsymbol{A}$. A large fascicle of OSNs converging into the glomerulus in which the mitral cell and the ET cell projected was first stimulated (stim 1). Then, the stimulating pipette was positioned at a more distant location in the nerve layer (stim 2). Stim $1(40 \mu \mathrm{A})$ evoked biphasic AMPAR-mediated EPSCs in the mitral cell and large EPSCs in the ET cell (black traces, top right). Distant stimulation evoked all-or-none slow-rising EPSCs in the mitral cell and monosynaptic EPSCs in the ET cell (gray traces, bottom right). Responses evoked by two intensities of stimulation (300 $\mu$ A and 2.3 $\mathrm{mA}$ ) had similar time courses and amplitudes. Inset, Zoom in the initial part of the mitral cell responses evoked in the two configurations.

tions) exist between mitral cells (Schoppa and Westbrook, 2002; Urban and Sakmann, 2002; Christie et al., 2005; Pimentel and Margrie, 2008; Maher et al., 2009) and between ET and mitral cells (De Saint Jan et al., 2009). In addition, we found that tufted cells from the external plexiform layer also evoke glutamatergic EPSCs on mitral cells (amplitude, $54 \pm 60 \mathrm{pA} ; 10-90 \%$ rise time, $3.4 \pm 1.7 \mathrm{~ms}$; half-width, $10.5 \pm 3.1 \mathrm{~ms} ; n=4$ pairs) (Fig. $5 A$ ). In our paired recordings (17 ET-mitral from our previous study, 4 tufted-mitral, 3 mitral-mitral), a common property of these NBQX-sensitive connections was their high reliability. When action potentials were evoked at $0.1-0.2 \mathrm{~Hz}$ in the presynaptic cell, failures were never observed, and EPSC amplitudes varied little in the postsynaptic cell (Fig. 5A-D) (De Saint Jan et al., 2009). Hence, dendritic release of glutamate by mitral, tufted, and ET cells likely mediates the robust feedforward excitation.

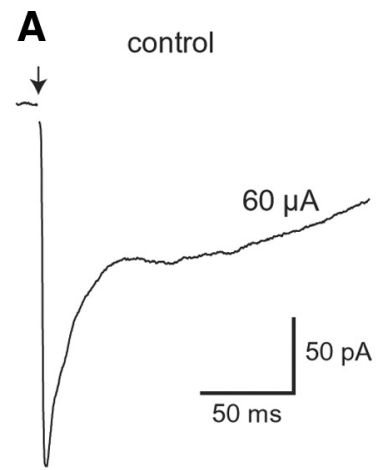

B

Normalized traces
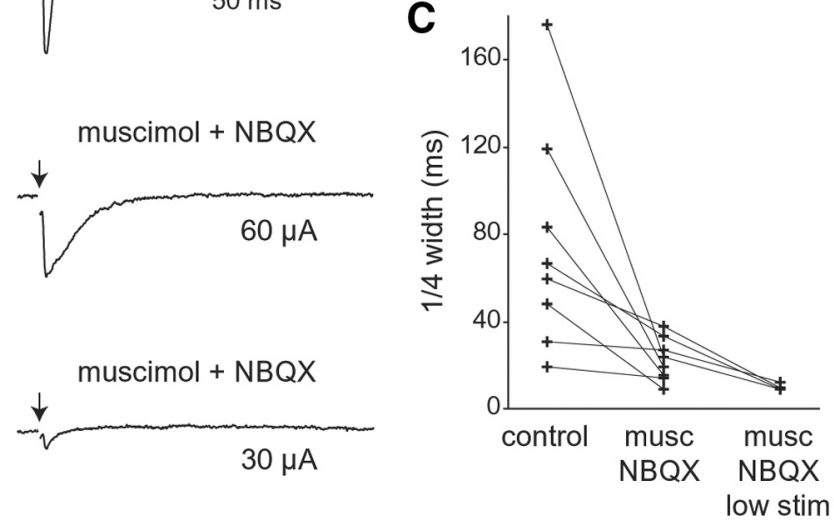

Figure 4. Conditions of low network excitability reduce the slow component of the AMPARmediated mitral cell response. A, AMPAR-mediated mitral cell responses recorded in control conditions (top trace, D-AP5 and CPCCOEt, stimulation $60 \mu \mathrm{A}$ ) and after the addition of muscimol $(1 \mu \mathrm{M})$ and NBQX (300 nM) at two stimulation intensities ( $60 \mu \mathrm{A}$, middle trace; $30 \mu \mathrm{A}$, bottom trace). $\boldsymbol{B}$, Same traces normalized at their peak. The response was shorter in conditions of low network excitability (muscimol + NBQX) but still biphasic. Only the EPSC evoked by the lower intensity was monophasic with a decay fitted with a monoexponential function (gray). Traces are averages from 5 to 15 individual responses. C, Summary plot for 8 cells in which the mixture muscimol (musc, 1-2 $\mu \mathrm{m}$ ) + NBQX (200-300 nm) was tested. In every case, this shortened the slow component of the response measured as the width of the response at $1 / 4$ of the peak. Lowering the stimulus intensity further reduced the length of the response in four of these cells.

\section{Feedforward inhibition modulates the slow component of the mitral cell EPSC}

The glomerular network also contains highly excitable inhibitory circuits which are likely to be activated during network activity (Murphy et al., 2005; Gire and Schoppa, 2009). We, thus, compared AMPAR-mediated mitral cell responses in the presence and absence of functional $\mathrm{GABA}_{\mathrm{A}}$ Rs. When gabazine was omitted from the recording solution, the response was sculpted by outward currents, as previously shown (Carlson et al., 2000). Gabazine inhibited these IPSCs and uncovered the slow excitatory current (Fig. 6A). IPSCs were evoked at all tested stimulation intensities, including near threshold $(n=5)$ (Fig. 6A), and were blocked by NBQX ( $n=4$; data not shown) demonstrating the feedforward nature of this pathway. Recordings of mitral cells near the equilibrium potential for AMPAR EPSCs revealed that this inhibition was asynchronous, lasted approximately the duration of the slow excitatory component, and occurred with a delayed onset ( $6.1 \pm 0.3 \mathrm{~ms}, n=5$ ) (Fig. $6 B$ ), suggesting it might effectively compete with feedforward excitation.

To test this hypothesis, we examined the effect of gabazine on the mitral cell discharge recorded in the cell-attached configuration to avoid interfering with the intracellular ionic concentration. Stimulus intensities in the same range as those used in whole-cell experiments evoked trains of action potentials (Fig. $7 A$ ) with the number of spikes increasing with the stimulus 
A
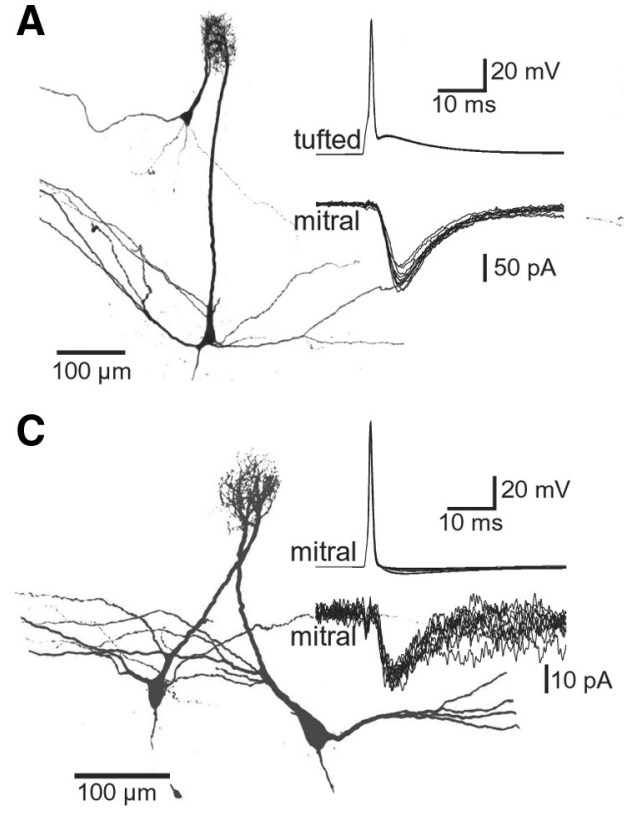

D

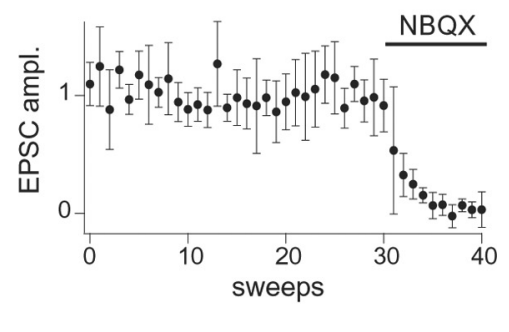

Figure 5. Mitral cells, tufted cells, and ET cells mediate a robust feedforward excitation. $A-C$, Biocytin-filled pairs between a mitral and a tufted cell $(\boldsymbol{A})$, a mitral and an ET cell $(\boldsymbol{B})$, and two mitral cells $(\boldsymbol{C})$ projecting into the same glomerulus. Action potentials in the presynaptic cell reliably produced EPSCs in the mitral cell (traces in insets). Eleven consecutives sweeps are shown for each pair. Note the absence of failure. $\boldsymbol{D}$, Normalized amplitudes over time of AMPAR-mediated EPS(s evoked by single spikes in five other pairs (1 $\mathrm{ET}$-mitral, 2 tufted-mitral, and 2 mitral-mitral).

strength (Fig. $7 B$ ). The first spike of these responses usually occurred within 3 and $10 \mathrm{~ms}$ after the stimulus, a timing that depended on the intensity of stimulation (Fig. $7 B$ ) but was not affected by gabazine (Fig. $7 A, C$ ). In contrast, gabazine increased the frequency and changed the timing of subsequent action potentials (Fig. $7 A, C$ ). Similar results were obtained in the presence or absence of NMDA and mGlu1 receptor blockers, although stimulation evoked much longer trains of spikes in regular ACSF (data not shown). Thus, the mitral cell discharge was also composed of two phases with a first spike most likely triggered by the direct OSN input whose timing depends only on the afferent activity and a delayed discharge modulated by synaptic processing in the glomerular network. We conclude that the sequence of axo-dendritic and dendro-dendritic synaptic events that mediates the mitral cell EPSC also shapes its output.

\section{Discussion}

Our experiments demonstrate that a stimulation of the olfactory nerve layer evokes a biphasic EPSC in postsynaptic mitral cells. The response is initiated by a fast monosynaptic OSN input and followed by a slow and robust feedforward excitation. This slow excitation relies on dendro-dendritic excitatory synapses with unusually high efficacy. The slow component is modulated by feedforward inhibition but provides a strong glomerular amplification of the afferent input.

These results clarify a controversy regarding the nature of the OSN-evoked mitral cell response. In our previous studies, we found that mitral cells respond to a stimulation of the sensory afferences with a LLD initiated by a fast monosynaptic EPSP/ EPSC. This LLD increased in amplitude and duration with the stimulus strength (De Saint Jan and Westbrook, 2007; De Saint Jan et al., 2009). The results reported in the present study are consistent with these reports. In contrast, in similar experiments other groups were never able to activate OSN to mitral cells

\section{Gire and Schoppa (2009)}

monosynaptic fast EPSCs. Instead, their stimulation evoked an all-or-none LLD with a slow-rising phase whose probability of being evoked depended on the stimulus intensity (Carlson et al., 2000; Gire and Schoppa, 2009). Gire and Schoppa (2009) suggested that the fast component seen in our experiments could reflect a direct electrical activation of the mitral cell primary dendrites. Here, we show that no current was seen in the presence of glutamate receptor antagonists or when the stimulating pipette was moved a few tens of micrometer away from the bundle of OSNs arguing against such artifact. Although these results do not rule out the possibility of a direct electrical stimulation of ET cell dendrites, it seems unlikely that this artifact would never affect a mitral cell projecting into the same glomerulus. Moreover, our functional and electron microscopy data undoubtedly demonstrate the presence of functional axo-dendritic synapses between OSNs and mitral cells. These results are consistent with previous ultrastructural studies (Pinching and Powell, 1971; Kosaka et al., 2001) and confirm the prevailing view (Shepherd, 2004) that was challenged by

The nature of the mitral cell response depended critically on the position of the stimulating pipette. A direct input was evoked when the stimulating pipette was positioned on a visible fascicle of OSNs entering the glomerulus. In contrast, it possibly disappeared when the stimulating pipette was positioned away from this major bundle. Under these conditions, EPSCs evoked in ET cells were relatively small (as those reported by Gire and Schoppa [2009], their Fig. 4) compared with those usually evoked by subthreshold on-beam stimulation, suggesting that the stimulus activated fewer OSNs. This is consistent with the anatomical organization of OSNs that converge in their glomerulus into discrete bundles of variable size that become thicker as they approach the glomerulus (Potter et al., 2001). The lack of direct OSN input in the mitral cell in these conditions, or when a visible OSN bundle was activated with a minimal stimulation, may reflect a higher density of OSN axons converging onto ET cells than onto mitral cells.

OSN stimulation evoked in mitral cells a monosynaptic input followed by a slower component of competing feedforward excitation and inhibition generated by intraglomerular networks. This response was graded because increasing the stimulation strength resulted in the recruitment of additional OSN axons. Surprisingly, even the weakest OSN input triggered a phase of feedforward excitation. The hyperexcitability of ET cells, the high degree of OSN convergence onto ET cells and the high efficacy of dendro-dendritic excitatory synapses are critical factors that promote the unique efficiency of this excitatory feedforward circuit. ET cells respond to weak OSN input with large monosynaptic EPSPs boosted by voltage-activated conductances (Liu and Shipley, 2008a). Consequently, OSN inputs that fail to evoke spike firing in mitral cells trigger bursts of action potentials in ET cells (De Saint Jan et al., 2009). Subsequent release of glutamate onto mitral cells (De Saint Jan et al., 2009) and probably tufted cells 
A
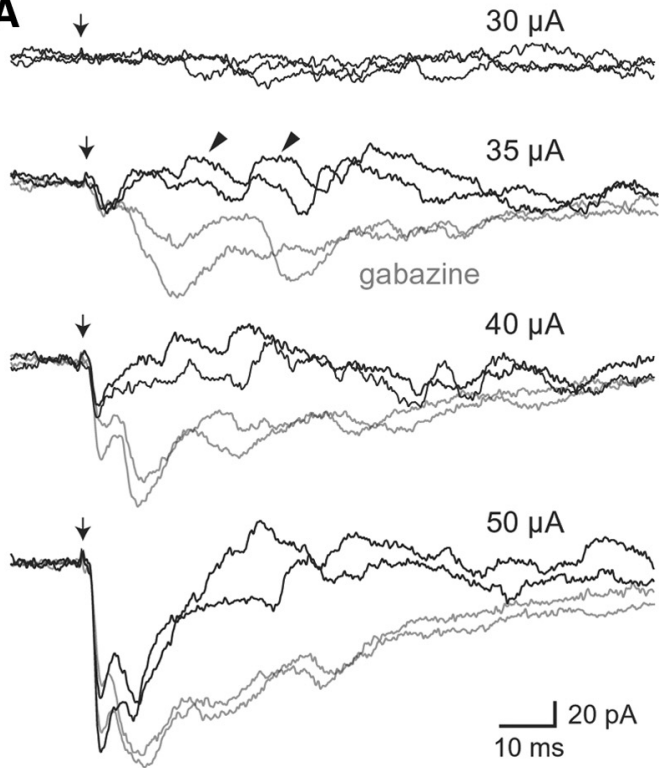

B

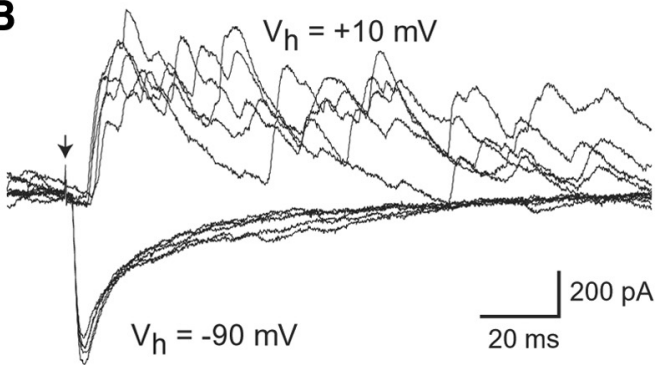

Figure 6. Stimulation of OSNs evokes a delayed feedforward inhibition. A, Mitral cell responses evoked by increasing intensities $(30-50 \mu \mathrm{A}$ as indicated) of OSN stimulation in the presence of CPCCOEt and D-AP5 before (black traces) and after the addition of gabazine ( $4 \mu \mathrm{M}$, gray traces). Individual traces recorded at a holding potential of $-70 \mathrm{mV}$ are superimposed. Note that even the weakest stimulus evoked asynchrounous IPSCS (arrowheads). B, Mitral cell responses recorded in the presence of $\mathrm{CPCCOEt}$ and D-AP5 at two holding potentials $-90 \mathrm{mV}$ and $+10 \mathrm{mV}$, i.e., the approximate reversal potential for AMPAR-mediated EPSCs. Five traces are superimposed in each condition. Note the delayed onset of feedforward inhibition.

(although the connection ET-tufted has not yet been demonstrated) should summate with the OSN direct input and might reach the threshold for mitral and tufted cells firing. These neurons would in turn release glutamate with a high reliability within the glomerular network. In our paired recordings, mitral-mitral, ET-mitral, and tufted-mitral failures of transmission were never seen, and amplitude of postsynaptic EPSCs varied little over time even for small EPSCs. This suggests that glutamate is released with a high probability at these excitatory dendro-dendritic synapses, a property that strongly favors recurrent excitation.

We have also shown that OSN inputs activate feedforward inhibitory circuits that are at least as excitable as the feedforward excitatory circuits. GABAergic periglomerular (PG) cells most likely mediate this feedforward inhibition. Several observations support this idea. First, the weak stimulations used in our study were local and probably activated only one or a few glomeruli as previously shown (McGann et al., 2005; Wachowiak et al., 2005). Some PG cells are highly excitable because of their repertoire of voltage-activated channels and their high input resistance $(\sim 1$ $\mathrm{G} \Omega$ ). As a result, weak OSN inputs that fail to activate glomerular excitatory circuits produce discharge in PG cells (Gire and Schoppa, 2009), and firing of a single ET cell can activate several PG cells (Murphy et al., 2005). Furthermore, stronger OSN stim-
A
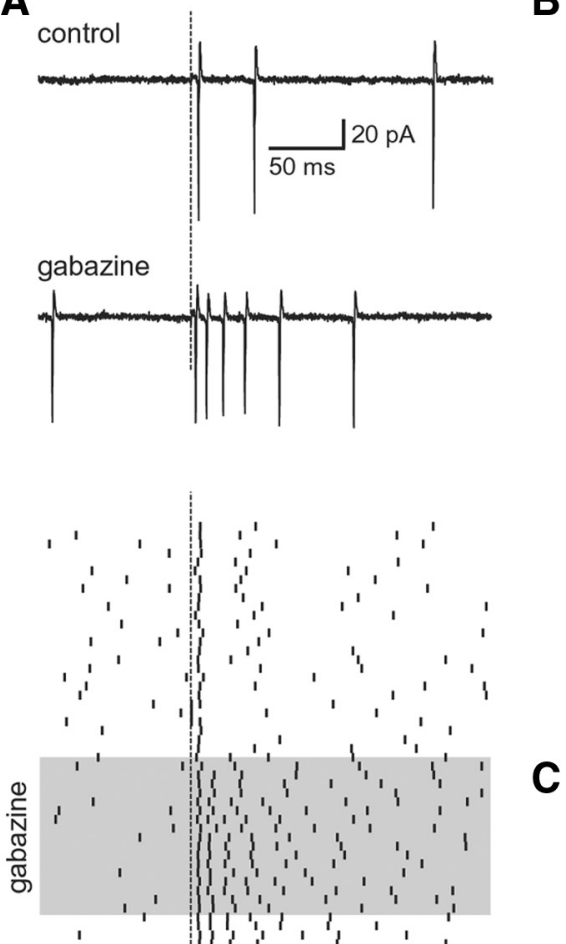

I

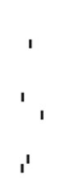

'

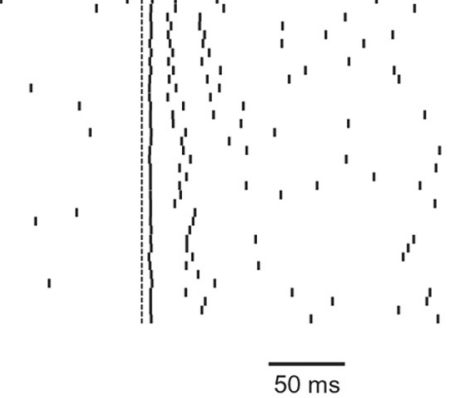

B
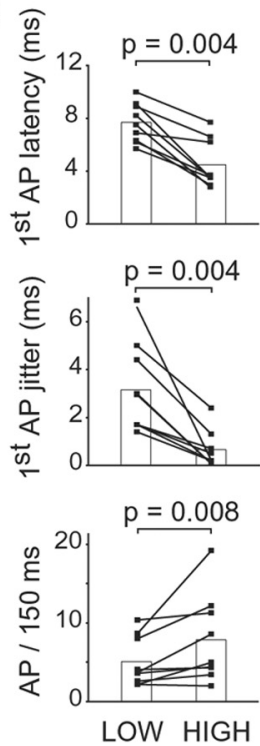

C
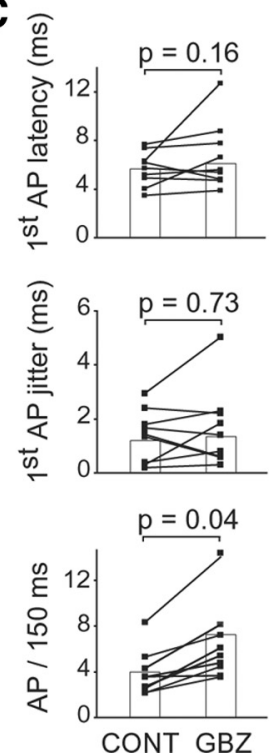

Figure 7. OSN-evoked mitral cell output is also biphasic. $A$, Cell-attached recording of a mitral cell discharge evoked by stimulation of OSNs (intensity $45 \mu \mathrm{A}$ ) in control conditions and in gabazine $(2 \mu \mathrm{m})$. Dashed line indicates the stimulation onset. Bottom, Raster plots of the responses for the same cell. Each red point indicates a spike. Consecutive sweeps are shown from top to bottom. Gray box indicates the period when gabazine was applied. Solutions for recording included D-AP5 and CPCCOEt. $\boldsymbol{B}$, The stimulation intensity modulated the latency (top graph) and the jitter (middle) of the first action potential of the train as well as the number of spikes counted across a $150 \mathrm{~ms}$ window after the stimulus (bottom). Summary data for nine mitral cells whose responses were recorded at low (20-60 $\mu \mathrm{A}$, left columns) and high (40$100 \mu \mathrm{A}$, right columns) stimulus intensities. C, The number of spikes during the first $150 \mathrm{~ms}$ after the stimulus (top graph) was significantly increased by gabazine (right column), whereas the jitter of the first action potential was not affected (bottom graph). Summary data for nine mitral cells recorded before and after the addition of gabazine ( $\mathrm{gbz}$ ). $\ln \boldsymbol{B}$ and $\boldsymbol{C}$, data from cells recorded in regular ACSF or in the presence of D-AP5 and CPCCOEt were pooled.

ulations that activate many glomeruli are required to drive granule cells, the other GABAergic neurons of the bulb circuitry that synapse with mitral cell lateral dendrites in the external plexiform layer (Gire and Schoppa, 2009). What is the function of this inhibition? Feedforward inhibitory circuits are ubiquitous in the brain (Shepherd, 2004). They often define an integration time window for coincident afferent inputs and regulate spike timing 
in principal cells (Pouille and Scanziani, 2001; Gabernet et al., 2005). In our experiments, glomerular inhibitory circuits effectively shaped the delayed component of the mitral cell output but did not modulate the timing of the first spike. However, unlike electrical stimulations that synchronizes inputs in vitro, odorants produce slow bursts of asynchronous sensory inputs in OSNs in vivo (Carey et al., 2009). Under these conditions, glomerular feedforward inhibition might also define an integration window for incoming sensory afferences and precisely regulate the timing of the first spike which can encode information about odorant identity and concentration (Margrie and Schaefer, 2003; Schaefer and Margrie, 2007; Wesson et al. 2008; Junek et al. 2010).

\section{References}

Carey RM, Verhagen JV, Wesson DW, Pírez N, Wachowiak M (2009) Temporal structure of receptor neuron input to the olfactory bulb imaged in behaving rats. J Neurophysiol 101:1073-1088.

Carlson GC, Shipley MT, Keller A (2000) Long-lasting depolarizations in mitral cells of the rat olfactory bulb. J Neurosci 20:2011-2021.

Chen WR, Shepherd GM (1997) Membrane and synaptic properties of mitral cells in slices of rat olfactory bulb. Brain Res 745:189-196.

Christie JM, Schoppa NE, Westbrook GL (2001) Tufted cell dendrodendritic inhibition in the olfactory bulb is dependent on NMDA receptor activity. J Neurophysiol 85:169-173.

Christie JM, Bark C, Hormuzdi SG, Helbig I, Monyer H, Westbrook GL (2005) Connexin36 mediates spike synchrony in olfactory bulb glomeruli. Neuron 46:761-772.

De Saint Jan D, Westbrook GL (2007) Disynaptic amplification of metabotropic glutamate receptor 1 responses in the olfactory bulb. J Neurosci 27:132-140.

De Saint Jan D, Hirnet D, Westbrook GL, Charpak S (2009) External tufted cells drive the output of olfactory bulb glomeruli. J Neurosci 29: 2043-2052.

Gabernet L, Jadhav SP, Feldman DE, Carandini M, Scanziani M (2005) Somatosensory integration controlled by dynamic thalamocortical feedforward inhibition. Neuron 48:315-327.

Gire DH, Schoppa NE (2009) Control of on/off glomerular signaling by a local GABAergic microcircuit in the olfactory bulb. J Neurosci 29: $13454-13464$.

Hayar A, Karnup S, Ennis M, Shipley MT (2004a) External tufted cells: a major excitatory element that coordinates glomerular activity. J Neurosci 24:6676-6685.

Hayar A, Karnup S, Shipley MT, Ennis M (2004b) Olfactory bulb glomeruli: external tufted cells intrinsically burst at theta frequency and are entrained by patterned olfactory input. J Neurosci 24:1190-1199.

Junek S, Kludt E, Wolf F, Schild D (2010) Olfactory coding with patterns of response latencies. Neuron 67:872-884.

Kasowski HJ, Kim H, Greer CA (1999) Compartmental organization of the olfactory bulb glomerulus. J Comp Neurol 407:261-274.

Kiyokage E, Pan YZ, Shao Z, Kobayashi K, Szabo G, Yanagawa Y, Obata K, Okano H, Toida K, Puche AC, Shipley MT (2010) Molecular identity of periglomerular and short axon cells. J Neurosci 30:1185-1196.

Kosaka K, Aika Y, Toida K, Kosaka T (2001) Structure of intraglomerular dendritic tufts of mitral cells and their contacts with olfactory nerve terminals and calbindin-immunoreactive type 2 periglomerular neurons. J Comp Neurol 440:219-235.

Liu S, Shipley MT (2008a) Intrinsic conductances actively shape excitatory and inhibitory postsynaptic responses in olfactory bulb external tufted cells. J Neurosci 28:10311-10322.

Liu S, Shipley MT (2008b) Multiple conductances cooperatively regulate spontaneous bursting in mouse olfactory bulb external tufted cells. J Neurosci $28: 1625-1639$.
Ma J, Lowe G (2007) Calcium permeable AMPA receptors and autoreceptors in external tufted cells of rat olfactory bulb. Neuroscience 144: $1094-1108$.

Maher BJ, McGinley MJ, Westbrook GL (2009) Experience-dependent maturation of the glomerular microcircuit. Proc Natl Acad Sci U S A 106:16865-16870.

Malnic B, Hirono J, Sato T, Buck LB (1999) Combinatorial receptor codes for odors. Cell 96:713-723.

Margrie TW, Schaefer AT (2003) Theta oscillation coupled spike latencies yield computational vigour in a mammalian sensory system. J Physiol 546:363-374.

McGann JP, Pírez N, Gainey MA, Muratore C, Elias AS, Wachowiak M (2005) Odorant representations are modulated by intra- but not interglomerular presynaptic inhibition of olfactory sensory neurons. Neuron 48:1039-1053.

Metzger F, Repunte-Canonigo V, Matsushita S, Akemann W, Diez-Garcia J, Ho CS, Iwasato T, Grandes P, Itohara S, Joho RH, Knöpfel T (2002) Transgenic mice expressing a $\mathrm{pH}$ and $\mathrm{Cl}$ - sensing yellow-fluorescent protein under the control of a potassium channel promoter. Eur J Neurosci 15:40-50.

Murphy GJ, Darcy DP, Isaacson JS (2005) Intraglomerular inhibition: signaling mechanisms of an olfactory microcircuit. Nat Neurosci 8:354-364.

Nagayama S, Takahashi YK, Yoshihara Y, Mori K (2004) Mitral and tufted cells differ in the decoding manner of odor maps in the rat olfactory bulb. J Neurophysiol 91:2532-2540.

Pimentel DO, Margrie TW (2008) Glutamatergic transmission and plasticity between olfactory bulb mitral cells. J Physiol 586:2107-2119.

Pinching AJ, Powell TP (1971) The neuropil of the glomeruli of the olfactory bulb. J Cell Sci 9:347-377.

Potter SM, Zheng C, Koos DS, Feinstein P, Fraser SE, Mombaerts P (2001) Structure and emergence of specific olfactory glomeruli in the mouse. J Neurosci 21:9713-9723.

Pouille F, Scanziani M (2001) Enforcement of temporal fidelity in pyramidal cells by somatic feed-forward inhibition. Science 293:1159-1163.

Ressler KJ, Sullivan SL, Buck LB (1994) Information coding in the olfactory system: evidence for a stereotyped and highly organized epitope map in the olfactory bulb. Cell 79:1245-1255.

Schaefer AT, Margrie TW (2007) Spatiotemporal representations in the olfactory system. Trends Neurosci 30:92-100.

Schoppa NE, Westbrook GL (2001) Glomerulus-specific synchronization of mitral cells in the olfactory bulb. Neuron 31:639-651.

Schoppa NE, Westbrook GL (2002) AMPA autoreceptors drive correlated spiking in olfactory bulb glomeruli. Nat Neurosci 5:1194-1202.

Shepherd GM (2004) The synaptic organization of the brain, Ed 5. Oxford: Oxford UP.

Urban NN, Sakmann B (2002) Reciprocal intraglomerular excitation and intra- and interglomerular lateral inhibition between mouse olfactory bulb mitral cells. J Physiol 542:355-367.

Vassar R, Chao SK, Sitcheran R, Nuñez JM, Vosshall LB, Axel R (1994) Topographic organization of sensory projections to the olfactory bulb. Cell 79:981-991.

Wachowiak M, Shipley MT (2006) Coding and synaptic processing of sensory information in the glomerular layer of the olfactory bulb. Semin Cell Dev Biol 17:411-423.

Wachowiak M, McGann JP, Heyward PM, Shao Z, Puche AC, Shipley MT (2005) Inhibition of olfactory receptor neuron input to olfactory bulb glomeruli mediated by suppression of presynaptic calcium influx. J Neurophysiol 94:2700-2712.

Wesson DW, Carey RM, Verhagen JV, Wachowiak M (2008) Rapid encoding and perception of novel odors in the rat. PloS Biol 6:717-729.

Wilson RI, Mainen ZF (2006) Early events in olfactory processing. Annu Rev Neurosci 29:163-201. 